\title{
An introduction to thin film processing using high-power impulse magnetron sputtering
}

Daniel Lundin and Kostas Sarakinos

\section{Linköping University Post Print}

N.B.: When citing this work, cite the original article.

Original Publication:

Daniel Lundin and Kostas Sarakinos, An introduction to thin film processing using highpower impulse magnetron sputtering, 2012, Journal of Materials Research, (27), 5, 780-792. http://dx.doi.org/10.1557/jmr.2012.8

Copyright: Cambridge University Press (CUP) / Materials Research Society http://www.mrs.org/

Postprint available at: Linköping University Electronic Press http://urn.kb.se/resolve?urn=urn:nbn:se:liu:diva-78284 


\title{
An introduction to thin film processing using high-power impulse magnetron sputtering
}

\author{
Daniel Lundin ${ }^{\text {a) }}$ and Kostas Sarakinos \\ Plasma \& Coatings Physics Division, IFM-Materials Physics, Linköping University, SE-581 83 Linköping, Sweden
}

(Received 16 July 2011; accepted 9 January 2012)

\begin{abstract}
High-power impulse magnetron sputtering (HiPIMS) is a promising sputtering-based ionized physical vapor deposition technique and is already making its way to industrial applications. The major difference between HiPIMS and conventional magnetron sputtering processes is the mode of operation. In HiPIMS the power is applied to the magnetron (target) in unipolar pulses at a low duty factor $(<10 \%)$ and low frequency $(<10 \mathrm{kHz})$ leading to peak target power densities of the order of several kilowatts per square centimeter while keeping the average target power density low enough to avoid magnetron overheating and target melting. These conditions result in the generation of a highly dense plasma discharge, where a large fraction of the sputtered material is ionized and thereby providing new and added means for the synthesis of tailor-made thin films. In this review, the features distinguishing HiPIMS from other deposition methods will be addressed in detail along with how they influence the deposition conditions, such as the plasma parameters and the sputtered material, as well as the resulting thin film properties, such as microstructure, phase formation, and chemical composition. General trends will be established in conjunction to industrially relevant material systems to present this emerging technology to the interested reader.
\end{abstract}

\section{INTRODUCTION}

The concept of plasma-based physical vapor deposition (PVD) is today widely used for depositing thin films. PVD is a general term describing how films are deposited by the condensation of a vaporized form of a material onto any surface. The vapor of the thin film material is created by physical means from a solid deposition source. One such PVD method is sputter deposition, ${ }^{1}$ which has proven to be a robust and upscalable coating method. The most commonly used tool for sputter deposition is magnetron sputtering, ${ }^{2,3}$ which essentially is a diode sputtering configuration where a magnet pack is placed behind the target (cathode) to better confine the plasma close to the sputtering region.

High-power impulse magnetron sputtering (HiPIMS) or sometimes referred to as high power pulsed magnetron sputtering (HPPMS) introduced by Kouznetsov et al. ${ }^{4}$ in 1999 is a promising technique for improving magnetron sputtering by the addition of pulsed power technology. ${ }^{5}$ To distinguish this technique from other pulsed magnetron processes, we use a similar definition as that of Anders ${ }^{6}$ : HiPIMS is pulsed magnetron sputtering, where the peak power exceeds the time-averaged power by typically two orders of magnitude. In addition, the HiPIMS technology has recently been industrially upscaled by several big

\footnotetext{
a) Address all correspondence to this author.

e-mail: daniel.lundin@liu.se

DOI: $10.1557 / j m r .2012 .8$
}

coating companies under various acronyms, which is a promising first step toward implementing it in common thin film processes. The interest of this technique has thus increased tremendously during the last 10 years, also shown by the steady increase of publications, reaching about 50 peer-reviewed scientific articles published in 2010 according to ISI Web of Science.

The main feature of HiPIMS is the combination of sputtering from standard magnetrons using pulsed plasma discharges, where the aim is to generate a highly ionized plasma with large quantities of ionized sputtered material. ${ }^{7}$ The high degree of ionization of the sputtered species has been shown to lead to the growth of smooth and dense elemental films ${ }^{8}$ as well as reactively deposited compound films ${ }^{9,10}$ and enable control over their phase composition, ${ }^{11}$ microstructure, ${ }^{12}$ as well as mechanical ${ }^{13}$ and optical $^{9,11}$ properties. It has also been reported to be beneficial in terms of improving film adhesion, ${ }^{14}$ enabling deposition of uniform films on complex-shaped substrates, ${ }^{15,16}$ and having a decreased deposition temperature. ${ }^{17}$ In summary, it is clear that the perspective of having advantages like the ones mentioned above is more than enough reason to continue developing new ionized sputtering techniques such as HiPIMS.

In this review, we have chosen to focus on the differences in process conditions as well as resulting thin film characteristics between HiPIMS and commonly used industrial PVD techniques, such as direct current magnetron sputtering (DCMS), radio frequency (RF) magnetron sputtering, and cathodic arc evaporation. The aim has 
been to provide a good introduction to this novel technique for PVD process engineers and researchers on thin films, who are familiar with the sputtering basics, without any claims on completely covering the whole field of HiPIMS. More details on the fundamentals and applications of HiPIMS can be found in the review articles by Helmersson et al., ${ }^{5}$ Sarakinos et al., ${ }^{18}$ and Anders. ${ }^{6}$ Furthermore, it should also be brought to the readers' attention that parts of the current review concerning thin film processing are based on a recent review paper by Sarakinos et al. ${ }^{18}$ Moreover, in this work, much attention has been paid to different industrially relevant material systems owing to the fact that they are after all the ultimate goal of any thin film deposition process.

\section{PROCESS CONDITIONS}

\section{A. How to create a highly ionized discharge}

In glow discharge processes such as magnetron sputtering, it is often difficult to achieve a large fraction of ionized sputtered material reaching the substrate. ${ }^{19-21}$ When the deposition flux consists of more ions than neutrals, the process is referred to as ionized PVD or IPVD. ${ }^{5}$ There are a few different IPVD techniques available today, such as postvaporization ionization using a secondary plasma generated by, for example, an RF coil placed in the deposition chamber to create ions that can be accelerated to the substrate surface when applying a negative bias. ${ }^{22}$ Another technique is the previously mentioned cathodic arc evaporation (see references 23 and 24), which uses the fact that very localized, extremely high current discharges can create a dense plasma resulting in a high degree of ionization around a particular spot. A third possibility is the use of hollow cathode magnetron sputtering. ${ }^{25,26}$ The hollow cathode traps electrons in a hollow cylinder or between two parallel plates. It works like two electrostatic mirrors reflecting electrons between the sheaths until they are thermalized through collisions, thus increasing the plasma density and the probability of ionizing any material passing through. ${ }^{27}$

Another approach to IPVD is to use HiPIMS, which is the focus of the present review. HiPIMS can be set up on a conventional magnetron sputtering system by changing power supplies making it possible to deliver high power pulses to the magnetron in the range of a few kilowatts per square centimeter while keeping the time-averaged power on a DCMS level of typically watts per square centimeter to avoid damaging the magnetron. ${ }^{18}$ Such a HiPIMS discharge pulse is shown in Fig. 1. The length of the pulse is often kept in the range $10-500 \mu \mathrm{s}^{28,29}$ with a pulse frequency from tens of hertz to kilohertz. 5,30 The applied voltage during the pulse in most HiPIMS processes is usually around 500-1000 V, and the peak current density (peak discharge current/target area) reaches at most a few amperes per square centimeter (see Ref. 31).

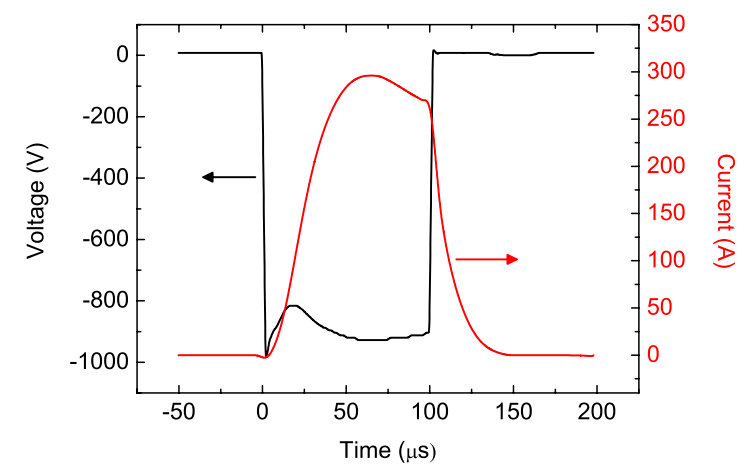

FIG. 1. Voltage and current characteristic for a typical high-power impulse magnetron sputtering (HiPIMS) discharge pulse. This discharge was generated using a 6" $\mathrm{Cu}$ target at $1.33 \mathrm{~Pa}$ Ar pressure. The peak current density is about $1.6 \mathrm{~A} \mathrm{~cm}^{-2}$.

\section{B. Plasma conditions}

The mechanism of transferring a process gas to a HiPIMS plasma can be seen as the analog of dielectric breakdown in an insulating solid, where the dielectrics will start conducting current at a critical voltage. In the case of the process gas it starts with free electrons, caused by background radiation or thermal energy, being accelerated toward the anode (chamber walls or the ground shield of the magnetron) by an electric field, created by the voltage difference applied between the cathode (target) and anode. The accelerated electrons will gain energy and eventually collide with neutral gas atoms, which in some cases will lead to ionization and the release of two free electrons per ionized atom (electron impact ionization). These two electrons can now collide with two other neutrals, whereas any gas ion present will be accelerated and collide with the cathode releasing, among other particles, electrons (referred to as secondary electrons). Eventually, this process leads to the breakdown of the process gas resulting in a plasma. Through the use of very high applied instantaneous power densities to the magnetron, there will be a tremendous increase of charge carriers in front of the target during the HiPIMS pulse. In numbers this means that for the HiPIMS discharge, the electron density in the ionization region close to the target surface is on the order of $10^{18}-10^{19} \mathrm{~m}^{-3} \cdot{ }^{32,33}$ For an electron density around $10^{19} \mathrm{~m}^{-3}$, the ionization mean free path of a sputtered metal atom is about $1 \mathrm{~cm}$, whereas for an electron density of $10^{17} \mathrm{~m}^{-3}$, commonly observed in a DCMS discharge, the ionization mean free path is $\sim 50 \mathrm{~cm}$ for typical discharge conditions. ${ }^{34}$ Thus, given the high electron density in the HiPIMS discharge a significant fraction of the sputtered material is thereby ionized, which also has been verified in a great number of publications. ${ }^{4,35-37}$ Worth pointing out is that there are substantial differences in the degree of ionization of the sputtered material depending on what target material is used (from a couple of percent to almost fully ionized ${ }^{36,38}$ ). The reason 
for this behavior is mainly related to the fact that the ionization potential is material dependent and for metals used in magnetron sputtering commonly found in the range $E_{\mathrm{IP}}=5.99 \mathrm{eV}(\mathrm{Al})$ to $E_{\mathrm{IP}}=11.26 \mathrm{eV}(\mathrm{C})$, meaning that $\mathrm{Al}$ is more easily ionized than $\mathrm{C}$. In plasma discharge modeling by both Hopwood ${ }^{39}$ and Samuelsson et al., these trends are clearly shown and in Fig. 2, one such example is illustrated for HiPIMS using a $100 \mu$ s discharge pulse of $-880 \mathrm{~V}$ and $30 \mathrm{~A}$ peak current (corresponding to a peak current density of about $1.5 \mathrm{~A} \mathrm{~cm}^{-2}$ ). As a reference, for DCMS discharges the degree of ionization is found to be $5 \%$ or less. ${ }^{39,40}$ Further discussions on the impact of a high degree of ionization of the sputtered material on the thin film growth will be given in Section III. Before continuing, a word of caution should be given regarding ionization, since there is occasionally some misunderstanding concerning reported values of the ionization of sputtered material, which often has to do with the fact that the degree of ionization of sputtered material (in the plasma), $n_{i} /\left(n_{i}+n_{n}\right)$, is not of the same value as the ionized flux fraction (flux of material reaching the substrate), $\Gamma_{i} /\left(\Gamma_{i}+\Gamma_{n}\right)$. This is because the ion flux is governed by the electron temperature, $T_{\mathrm{e}}$, and the neutral flux by the gas temperature, $T_{\mathrm{g}}$. For partially ionized plasma discharges, such as the HiPIMS discharge, $T_{\mathrm{e}}$ is often significantly larger than $T_{\mathrm{g}}$ (in HiPIMS the dense process gas, $n_{\mathrm{Ar}} \sim 10^{20} \mathrm{~m}^{-3}$, is far from being completely ionized thus affecting $T_{\mathrm{g}}$ ). This means that the ion flux fraction is larger than the degree of ionized metal and therefore it is not uncommon to find that although the degree of ionization only reaches about $50 \%$, the ionized flux fraction at the substrate can be more than $90 \%{ }^{8}$

The HiPIMS plasma has also shown the presence of multiply charged ions for various target materials, ${ }^{7,41-44}$ which is rarely found in other types of magnetron discharges but often found in cathodic arc discharges. ${ }^{45}$

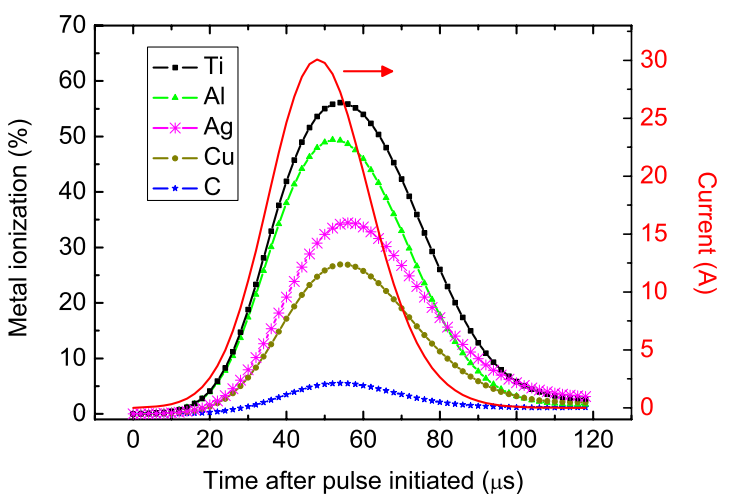

FIG. 2. A comparison of the evolution of the degree of metal ionization for different target materials from a global plasma model. The discharge current peaks at about $30 \mathrm{~A}$ at $\sim 50 \mu$ s into the pulse (the peak current density is about $1.5 \mathrm{~A} \mathrm{~cm}^{-2}$ ). A $100 \mu$ s square voltage pulsed of $-880 \mathrm{~V}$ was used in the modeling (from Samuelsson et al. ${ }^{8}$ with permission from Elsevier).
One implication of having this type of ions is that they enable sustained self-sputtering, ${ }^{6}$ meaning that they will sputter enough material for continued ionization and release enough secondary electrons to keep the plasma burning assuming that enough sputtered metal ions can be attracted back to the target. For high yield materials such as $\mathrm{Cu}$ this has led to the onset of self-sputtering regimes characterized by a second increase of the discharge current beyond the value of the initial peak current, if the pulse is sustained for a long enough time in combination with high negative discharge voltages. ${ }^{43,46}$ The singly ionized sputtered atoms cannot contribute to this process, since they often do not exceed the ionization energy threshold required for the release of secondary electrons into the plasma. This has led to the possibility that HiPIMS processes can be run without the use of a process gas, which opens up the field of ultraclean sputtering. ${ }^{47}$ Having multiply charged ions in the plasma might also lead to a high energy bombardment of the growing film, since ions will be accelerated in the plasma sheath between the bulk plasma and the substrate. An applied substrate bias of $-50 \mathrm{~V}$ will, for example, accelerate a doubly charged ion to $100 \mathrm{eV}$, which might lead to implantation of the primary (incoming) species. ${ }^{48}$ This in turn may induce compressive stress as the bombarding species are distorting the lattice of the sputtered films, ${ }^{1}$ which might cause the film to peel off. Therefore, one has to take care when running a process containing these types of ions.

Moreover, the metal ions generated in the HiPIMS plasma are found to be highly energetic. ${ }^{7}$ From ionenergy measurements in HiPIMS discharges, it has been found that the average ion energy in the bulk plasma during the discharge pulse is around $20 \mathrm{eV}$ without the use of any substrate bias. ${ }^{7,49}$ As it turns out, ion energies in the range of 20-30 eV have been shown to have a densifying effect on thin films,${ }^{50}$ which is a very fortunate result and will be explored further in Section III C dealing with thin film growth. In Fig. 3, the ion-energy distributions for HiPIMS and DCMS for $\mathrm{Ti}^{+}$ions are compared. In the case of HiPIMS, a high energy part around $10-15 \mathrm{eV}$ is clearly detected followed by a high energy tail. Last, from measurements by Hecimovic and Ehisarian ${ }^{51,52}$ on the ion-energy distribution for various metals as well as for $\mathrm{Ar}$, it is also seen that ions are long-lived in the HiPIMS discharge and in some cases present during the entire pulseoff time (up to $10 \mathrm{~ms}$ ), although there is an exponential ion density decrease. The ion energy and life span of ions are found to depend strongly on collisions of the sputtered flux with the surrounding gas and as such depends on the target material, where light elements, such as $\mathrm{C}$ and $\mathrm{Al}$, lose more energy in collisions with $\mathrm{Ar}$ atoms and thereby have a shorter lifetime than heavy elements, for example, $\mathrm{Nb} .^{51,52}$ The implications of having ion bombardment of the thin film during the off-time of the HiPIMS pulse have so far not been investigated. One should also bear in mind that 


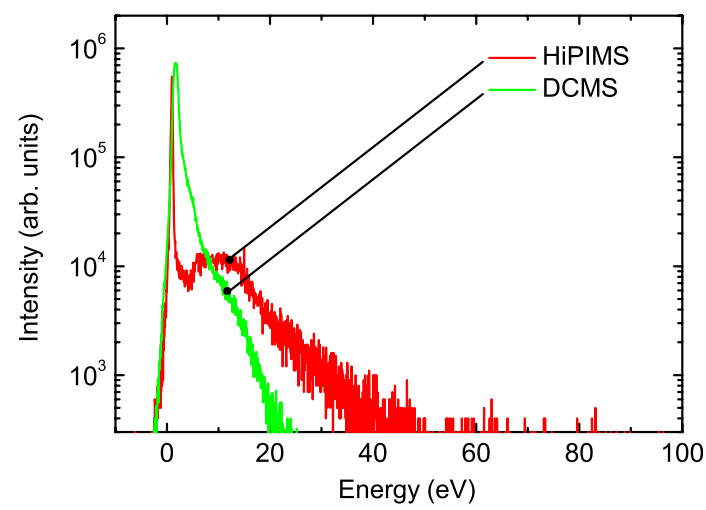

FIG. 3. Comparison between $\mathrm{Ti}^{+}$ion-energy distributions from HiPIMS and direct current magnetron sputtering (DCMS) measured at $0.80 \mathrm{~Pa} \mathrm{Ar}$ under equivalent process conditions at the same average power. The distributions have been normalized to fit into one single plot. Reprinted from Lundin et al. ${ }^{49}$ with permission from the Institute of Physics.

deposition takes place during the pulse-off time because of the time needed for sputtered material to reach the substrate.

Table I sums up a few important parameters for the HiPIMS process. They are not to be seen as exact values but rather a help to determine what type of discharge one is dealing with.

Another important aspect of having an energetic flux of ions bombarding the substrate is the total energy flux, which affects the growing film. Furthermore, the heating due to energetic particle bombardment might melt thermally sensitive substrates, such as plastics. Comparative studies of the energy flux in HiPIMS and DCMS have shown that the total energy flux is of the same order ${ }^{53}$ or lower ${ }^{54,55}$ in the case of HiPIMS sputtering. This difference can be explained by the lower deposition rate for HiPIMS resulting in fewer bombarding particles per time unit (see Section II D). As an example, taking the lower deposition rate into account in the case of Ti sputtering using HiPIMS and DCMS, it has been concluded that $\sim 90 \%$ more energy per incoming particle is deposited on the substrate in the HiPIMS case. ${ }^{54}$ Furthermore, from absolute temperature measurements at the substrate position during a HiPIMS process, it was found that the maximum equilibrium temperature reached about $70{ }^{\circ} \mathrm{C} .{ }^{54}$ Although having an intense metal ion bombardment, this is well below the limit for several thermally sensitive substrates, which are thermally stable up to around $150^{\circ} \mathrm{C}$ (Kapton). ${ }^{54}$ In this example, the average power was $500 \mathrm{~W}$ on a 6" Ti target and a peak current density of about $1.5 \mathrm{~A} \mathrm{~cm}^{-2}$.

\section{Gas dynamics}

During the transport of both metal neutrals and ions, there is a certain probability that these particles will collide with the neutral gas background. These collisions lead to heating of the gas followed by expansion (decrease in gas
TABLE I. A summary of important parameters for the high-power impulse magnetron sputtering discharge. The plasma parameters are obtained from the dense plasma region a few centimeters from the target, where the ionization is expected to be the strongest (ionization region).

\begin{tabular}{ll}
\hline \hline \multicolumn{1}{c}{ Parameter } & \multicolumn{1}{c}{ Value } \\
\hline Peak power density & $10^{3} \mathrm{~W} \mathrm{~cm}^{-2}$ \\
Average power density & $1-10 \mathrm{~W} \mathrm{~cm}^{-2}$ \\
Peak current density & $1-10 \mathrm{~A} \mathrm{~cm}^{-2}$ \\
Discharge voltage & $500-1000 \mathrm{~V}$ \\
Pulse frequency & $10-1000 \mathrm{~Hz}$ \\
Pulse width & $10-500 \mu \mathrm{s}$ \\
Process gas pressure & $10^{-3}-10^{-2} \mathrm{Torr}(0.1-1 \mathrm{~Pa})$ \\
Magnetic field strength & $0.010-0.100 \mathrm{~T}$ \\
Electron density & $10^{18}-10^{19} \mathrm{~m}^{-3}$ \\
Electron temperature & $1-5 \mathrm{eV}$ \\
Ion energy (average for metal ions) & $20 \mathrm{eV}$ \\
Debye length & $10^{-6}-10^{-5} \mathrm{~m}$ \\
Electron gyroradius & $10^{-4}-10^{-3} \mathrm{~m}$ \\
Ion gyroradius & $10^{-1} \mathrm{~m}$ \\
Ionization mean free path & $10^{-2} \mathrm{~m}$ \\
\hline \hline
\end{tabular}

density in front of the target) in a process that is called gas rarefaction. It has extensively been investigated in magnetron discharges both experimentally and theoretically $^{56-60}$ during the last three decades. The loss of process gas results in a reduction of ions available for sputtering (often Ar ions) leading to a reduced deposition rate as well as a reduction of plasma density, which means that the desired IPVD properties will be lost. ${ }^{29}$

The reduction of gas density would not be much of a problem if the refill process would be fast enough. Unfortunately, this does not seem to be the case in all types of magnetron discharges, ${ }^{29}$ and it is believed to be particularly serious in HiPIMS due to the high peak power densities, ${ }^{61}$ which is further investigated and discussed in more detail in Ref. 29. Also, a fraction of reflected gas neutrals moving away from the target surface will collide with the neutral background and thereby enhance the gas rarefaction. Last, note that neutral gas atoms are also rapidly lost through direct ionization during the HiPIMS pulse. $^{29}$ This is a process, where gas ions arriving at the target become neutralized and reflected in the sputtering event, but are energetic enough to pass quickly through the near-cathode region and thus effectively drain the ionization region of process gas. To what extent it affects the overall gas depletion remains to be investigated. Conditions leading to loss of process gas will be discussed in Section II E regarding different pulse configurations.

\section{Deposition rate}

The lower deposition rate for HiPIMS compared to DCMS for the same average power is a drawback and is one of the most discussed topics in this field of research. In a recent report by Samuelsson et al., ${ }^{8}$ it was found that the rates are typically in the range of $30-80 \%$ compared to 
DCMS depending on target material. In Fig. 4, reported deposition rates are given for various target materials based on the data from Helmersson et al. ${ }^{62}$ and Samuelsson et al. ${ }^{8}$ The most common explanation to the reduction in deposition rate stems from a work by Christie, ${ }^{63}$ where back-attraction of metal ions to the target followed by selfsputtering causes a reduction in the amount of sputtered particles reaching the substrate. Controlling and optimizing the potential profile in the cathode region will, therefore, greatly affect the number of metal ions incident on the target surface, ${ }^{64}$ which so far has not been fully explored. Gas rarefaction, which was discussed in the previous section, is also likely to affect the deposition rate in HiPIMS processes. In addition, Konstantinidis et al. ${ }^{65}$ found that the amount of ions reaching the substrate is increased by increasing the plasma conductivity, which was seen by creating a secondary plasma between the magnetron and the substrate using an external inductive coil. Furthermore, Bugaev et al. ${ }^{66}$ and Bohlmark et al. ${ }^{67}$ showed that the magnetic confinement of the sputtered material affected the deposition rate. In a recent publication by Mishra et al., ${ }^{68}$ it is reported that the deposition rate at the substrate position could be increased six times by weakening the magnetic field strength at the target surface by $\sim 33 \%$. Emmerlich et al. ${ }^{69}$ highlighted the nonlinear energy dependence of the sputtering yield, meaning that it does not make sense to compare HiPIMS and DCMS deposition rates for the same average power, if not taking this dependence into account. When comparing with experimental results, they saw trends confirming their experiments, but it could not fully explain the differences. Another possibility is a recently discovered fast charged particle transport operating in pulsed plasma discharges such as HiPIMS. ${ }^{70,71}$ It results in an increase of

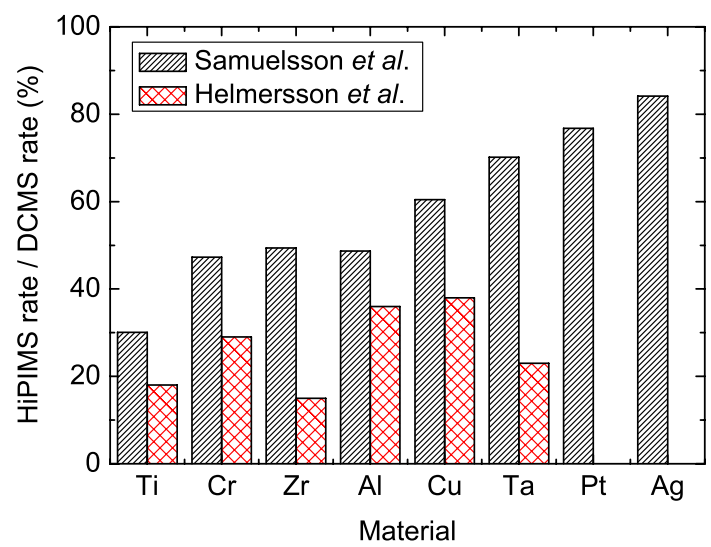

FIG. 4. Relative deposition rates for HiPIMS as compared to DCMS for various metal targets deposited at approximately the same average power. In the study by Samuelsson et al., ${ }^{8}$ the depositions were carried out at $0.67 \mathrm{~Pa}$ Ar pressure at a HiPIMS peak current density of $1.5 \mathrm{~A} \mathrm{~cm}^{-2}$. In the study by Helmersson et al., ${ }^{62}$ the process conditions could not be found (Data taken from Helmersson et al. ${ }^{62}$ and Samuelsson et al. ${ }^{8}$ with permission from Elsevier). ions being transported parallel to the target surface and lost to the walls instead of arriving at the substrate position, and thus reducing the deposition rate. ${ }^{49}$ Ongoing work on plasma modeling of HiPIMS discharges, where one can arbitrarily turn on and off mechanisms believed to affect the deposition rate, will most likely shed more light on the subject. ${ }^{72}$ Last, it should be pointed out that there are many situations where the quality of the coating is far more important than the deposition rate and one should, as always, be careful when making these comparisons based on only one or a few properties.

\section{E. Pulse configuration}

Often the question regarding what type of HiPIMS pulse to use arises. One answer is that it depends on what one wants to achieve in the deposition process. Below is a short summary of what process conditions that should be expected for a given pulse-type. In all cases, we assume that the above definition of HiPIMS still holds, meaning that we still are working with a considerable peak power density compared to the average power.

(1) $t_{\text {pulse }}<50 \mu \mathrm{s}$ : In short pulses, Ar ions are the dominant sputtering particles. ${ }^{29}$ Konstantinidis et al. ${ }^{28}$ have shown that by decreasing the pulse length it is possible to increase the deposition rate, where $\sim 70 \%$ of the DCMS deposition rate is achieved for $5 \mu$ s pulses in the case of $\mathrm{Ti}$ compared to $\sim 20 \%$ of the DCMS deposition rate for $20 \mu \mathrm{s}$ pulses, mainly due to less self-sputtering for short pulses. At the same time there is a tradeoff with the degree of ionization, where the highest reported values are found for the $20 \mu$ s pulses. ${ }^{28}$ It is also reported that shorter pulses have beneficial consequences for reactive HiPIMS processes, ${ }^{73}$ which are discussed in more detail in Section II F.

(2) $\mathrm{t}_{\text {pulse }} \sim 50-200 \mu \mathrm{s}$ : The most commonly used pulse width is $\sim 80-100 \mu \mathrm{s}$, which is enough time to develop high peak currents leading to many of the desired properties discussed in this work. As the pulse is prolonged, it is more likely that a fraction of the ionized sputtered material is attracted back to the target surface and will participate in the sputtering process (selfsputtering). ${ }^{63}$ This means that less sputtered material will reach the substrate, and the deposition rate is reduced. ${ }^{74}$

(3) $t_{\text {pulse }} \sim 200-500 \mu \mathrm{s}$ : Here, gas heating leading to dissipation of the gas in front of the target may seriously affect the discharge conditions (see discussion in Section II C), which often leads to a dramatic drop of the discharge current ${ }^{29,75}$ unless self-sputtering can compensate for the reduction of ions available for sputtering.

(4) $t_{\text {pulse }}>500 \mu \mathrm{s}$ : Longer pulsed regimes, where the discharge is sustained for several milliseconds, have been achieved when using the modulated pulsed power (MPP) technique, where the duty cycle can reach almost $30 \%$ compared to $1-10 \%$ for conventional HiPIMS discharges. ${ }^{76}$ In general, this limits the peak current that can be achieved 
to avoid damaging the magnetron, which means that the peak plasma density is limited to around $10^{17}-10^{18} \mathrm{~m}^{-3},{ }^{77}$ and the degree of metal ionization is found to be lower compared to shorter HiPIMS pulses. ${ }^{78}$ Still, the perspective of using multiple pulse packets within the same MPP pulse may result in facilitating the ignition of the plasma. ${ }^{78}$

In addition, the amplitude of the HiPIMS discharge current density is a good indicator for metal ionization, where an increasing discharge current density results in increased ionization ${ }^{31}$ and also an increased number of multiply charged ions. ${ }^{79}$ On the other hand, the applied voltage determines the energy of the sputtering ion, meaning that an increased applied voltage will increase the ion energy and thereby increase the number of sputtered particles. It is important to keep in mind that the sputter yield roughly scales as $\sqrt{V_{D}}$, ${ }^{69}$ where $V_{\mathrm{D}}$ is the applied discharge voltage, suggesting that the best choice to increase the deposition rate is not always to increase the applied voltage but, for example, increase the pulse frequency.

\section{F. Reactive HiPIMS}

In reactive sputtering processes, a reactive gas (e.g., $\mathrm{O}_{2}, \mathrm{~N}_{2}$, etc) is used along with the buffer gas to synthesize compound films. Typical for these processes is that the formation of the compound material takes place on the surface of the target (referred to as target coverage or poisoning). ${ }^{80,81}$ This layer is then sputtered and transported to the substrate to form the compound film. Deposition from a fully covered target (referred to as the compound sputtering mode) allows for growth of stoichiometric compound films, i.e., compound films with sufficient incorporation of the reactive gas atoms. ${ }^{80,81} \mathrm{At}$ these conditions, deposition rates lower than those obtained from an elemental (e.g., metallic) target are commonly achieved. ${ }^{80,81}$ Growth of stoichiometric compound films with relatively high rates can be facilitated in the intermediate target coverage regime (referred to as transition zone) between the metallic and the compound mode. ${ }^{80,81}$ In reactive DCMS, the transition sputtering zone is frequently unstable, and a hysteresis in the process parameters (i.e., target voltage, deposition rate, and reactive gas partial pressure) is often observed. ${ }^{80,81}$ This is particularly pronounced during reactive DCMS of metal oxides. ${ }^{82}$ As a consequence, stoichiometric films can only be obtained in the compound sputtering mode, ${ }^{80,81}$ unless a feedback system for controlling the target coverage is used. ${ }^{83}$ Investigations of the process characteristics during reactive HiPIMS of $\mathrm{Al}_{2} \mathrm{O}_{3},{ }^{30,73} \mathrm{ZrO}_{2},{ }^{84}$ and $\mathrm{CeO}_{2}{ }^{73}$ have shown that these processes can exhibit a hysteresis-free and stable transition zone at deposition conditions which in the case of DCMS result in hysteresis and an unstable transition zone, see Fig. 5 for $\mathrm{Al}_{2} \mathrm{O}_{3}$. The stabilization of the transition zone allows for deposition of stoichiometric films at a lower target coverage when compared to the compound mode in DCMS..$^{30,73,84}$ This has been shown to result in deposition rates similar ${ }^{30}$ or up to two times higher ${ }^{84}$ than those obtained by DCMS. It is worth mentioning that all the studies on reactive HiPIMS have been performed in small-size laboratorial scale deposition systems. The ability of HiPIMS to stabilize the transition zone and suppress/eliminate the hysteresis effect for large industrial size systems has still to be demonstrated.

In general, the stability of the transition zone in reactive sputtering processes is determined by the competition between the formation and the removal (sputtering) of the compound from the target surface. ${ }^{80,81}$ According to the formalism developed by Berg and Nyberg, ${ }^{80}$ the steadystate target coverage, $\vartheta_{t}$, is equal to

$$
\frac{J_{i} Y_{c} \vartheta_{t}}{q}=a 2 F\left(1-\vartheta_{t}\right)
$$

where $J_{\mathrm{i}}$ is the ion target current density, $Y_{\mathrm{c}}$ the compound sputtering yield, $q$ the elementary charge, $a$ the sticking coefficient of the reactive gas, and $F$ the flux of the reactive gas molecules toward the target. Stabilization of the transition mode can be achieved, if for a certain nominal

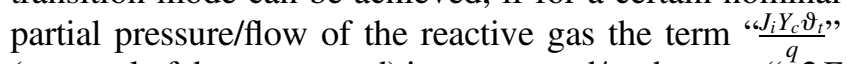
(removal of the compound) increases and/or the term " ${ }^{q} a 2 F$ $\left(1-\vartheta_{t}\right)$ " (formation of the compound) decreases. It has been suggested that the pulsed character of the HiPIMS discharge affects both terms in Eq. (1). In addition, the absence of plasma during the pulse-off time results in a limited activation of the reactive species. ${ }^{85}$ The expected

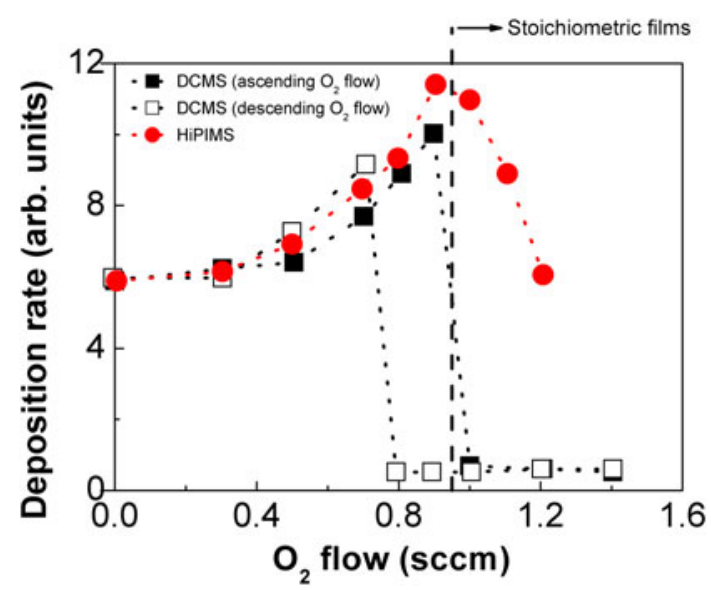

FIG. 5. Deposition rates obtained from an Al target sputtered using DCMS and HiPIMS in an $\mathrm{Ar}-\mathrm{O}_{2}$ atmosphere as measured by a quartz crystal microbalance. The filled and hollow squares correspond to the DCMS rate for increasing and decreasing $\mathrm{O}_{2}$ flow, respectively. It is seen that the DCMS process exhibits an unstable transition zone with pronounced hysteresis. On the contrary, the HiPIMS process (filled circles for both increasing and decreasing $\mathrm{O}_{2}$ flow) is stable and hysteresis-free. This behavior allows for a deposition rate similar to that obtained by DCMS (Data taken from Wallin and Helmersson ${ }^{30}$ ). 
life time of atomic species created during the HiPIMS discharge is $\sim 2 \mathrm{~ms}$ based on the experimental results by Clarenbach et al. ${ }^{86}$ Under these conditions, relatively high levels of reactive gas exposure are necessary for the formation of the compound on the target surface, i.e., this mechanism leads to lower effective values of the sticking coefficient $a$ in Eq. (1). Furthermore, the high peak target current in HiPIMS results in rarefaction of the neutral species in the target's vicinity, as discussed in Section II C, which affects not only Ar gas but also the reactive gas. ${ }^{87,88}$ The rarefaction implies that the reactive species flux $F$ is lower than the value corresponding to the nominal partial pressure of the reactive gas. ${ }^{87,88}$

\section{THIN FILM PROCESSING}

In magnetron sputtering techniques, variation of the deposition parameters allows for control of the energy transferred to the film-forming species enabling the manipulation of the film properties. ${ }^{1,89}$ Among the various ways used to provide energy to the growing film, bombardment by ionized species is widely used. ${ }^{39,90}$ Numerous studies have shown that during the film growth, the plasmafilm interface is affected by the energy of the bombarding ions, their flux, their nature, and their angle of incidence. ${ }^{91,92}$ These parameters determine the efficiency of the momentum transfer to the film atoms ${ }^{93}$ and have been shown to have implications on the film microstructure ${ }^{91}$ as well as on mechanical, optical, and electrical properties. ${ }^{90,94,95}$ In HiPIMS, high pulsed ion fluxes are made available at the substrate. In the next sections the effect of the energetic bombardment during HiPIMS on the growth and the properties of elemental and compound films is reviewed.

\section{A. Deposition on complex-shaped substrates}

The deposition of homogeneous films on substrates of complex geometry is a requirement for many technological applications, such as metallization of submicrometer patterns in optical and semiconductor devices ${ }^{96,97}$ and deposition of thick protective layers on forming tools and turbine blades. ${ }^{98,99}$ In conventional sputtering techniques such as DCMS the deposition flux is highly anisotropic $^{97,100}$ leading to inhomogeneous deposition, porosity, and poor coverage on substrate sites located along low flux directions. ${ }^{97}$ To alleviate these problems, highly ionized deposition fluxes can be used, since the trajectories of charged species can be manipulated by electric and magnetic fields. Different state-of-the-art attempts to achieve such conditions were discussed in Section II A.

HiPIMS provides an alternative approach to successfully deposit films on complex-shaped substrates. In Fig. 6, scanning electron microscopy (SEM) images of the crosssection of Ta films deposited both by DCMS and HiPIMS on a negatively biased $(-50 \mathrm{~V}) \mathrm{Si}$ substrate clamped on the side of a trench with an area of $1 \mathrm{~cm}^{2}$ and a depth of $2 \mathrm{~cm}$ are presented. ${ }^{15}$ The SEM images were taken from a position at the middle of the trench as shown in the sketch in Fig. 6. The DCMS grown film exhibits a porous columnar structure with columns tilted from the normal of the $\mathrm{Ta} / \mathrm{Si}$ interface [Fig. 6(b)], whereas the HiPIMS films are dense with columns growing perpendicularly to the Ta/Si interface [Fig. 6(a)]. This concept has been, for instance, used to deposit homogeneous hard nitride coatings on cutting inserts. ${ }^{98}$ Smaller features, such as holes of several tens or hundreds of nanometers can also be successfully filled ${ }^{101}$ or homogeneously coated. ${ }^{4}$ It has to be pointed out here that all studies performed so far concerned deposition of metallic films on biased conductive substrates.

\section{B. Phase composition tailoring by HiPIMS}

The phase composition of films is crucial for their mechanical, electrical, and optical performance. In sputtering processes, relatively low-growth temperatures and high deposition rates result in limited assembly kinetics. ${ }^{1,102}$ This in combination with extremely high cooling rates $\left(10^{13} \mathrm{Ks}^{-1}\right)$ during the condensation of the vapor on the substrate leads to nonequilibrium growth. ${ }^{1,102}$ Thus, the variation of both thermodynamic and kinetic conditions during deposition enables tailoring of the phase composition. Numerous studies have demonstrated that

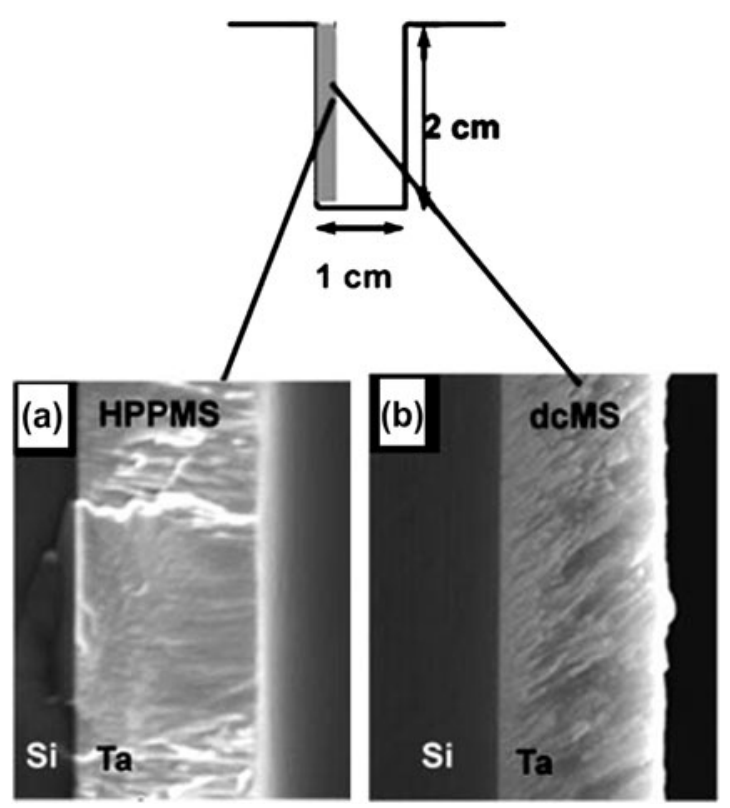

FIG. 6. Cross-sectional scanning electron microscope (SEM) images of Ta films grown by (a) HiPIMS and (b) DCMS on a Si substrate clamped on the side of a trench with an area of $1 \mathrm{~cm}^{2}$ and a depth of $2 \mathrm{~cm}$. The HiPIMS deposited film is dense with columns growing perpendicular to the Ta/Si interface. The DCMS deposited films have a porous microstructure with columns inclined toward the flux direction. Reprinted from Alami et al. ${ }^{15}$ with permission from the American Institute of Physics. 
energetic ions can be used for this purpose since they can trigger surface and bulk diffusion processes, ${ }^{1,102}$ induce changes in the film structure and chemical composition, ${ }^{103}$ and cause generation of internal stresses. ${ }^{104-107}$

The high fluxes of ionized material available in HiPIMS have been found to allow for control of the phase formation in both elemental and compound films. One example is the control of the phase composition in Ta films. ${ }^{12}$ In this case, tailoring of the phase formation is achieved by controlling the magnitude of the internal stresses. ${ }^{12}$ This process is particularly efficient in HiPIMS discharges owing to the degree of ionization of the Ta vapor of up to $70 \%{ }^{5}$ Ta forms both a low resistivity bodycentered cubic crystal structure (also known as the $\alpha$ phase) at elevated temperatures and a metastable high resistivity tetragonal phase $(\beta-\mathrm{Ta})$ at room temperatures. ${ }^{108,109}$ The abundance of $\mathrm{Ta}^{+}$ions in the deposition flux during the HiPIMS deposition of Ta films implies a more efficient momentum transfer to the growing surface. $^{12,92}$ This is in contrast to the growth by DCMS, where the majority of the ions in the deposition flux consists of the much lighter $\mathrm{Ar}^{+}$ions. ${ }^{19}$ HiPIMS thus provides tools for better influencing the internal stresses of the growing Ta films and accordingly the possibility to deposit $\alpha$-Ta films at room temperature (Fig. 7). ${ }^{12}$

In HiPIMS discharges, part of the ions moves along off-normal, with respect to the target, directions ${ }^{49}$ (see Section II D). This anomalous ion transport results in differences in the flux, the energy, and the composition of the deposited and bombarding species as functions of the deposition angle. Moreover, in the case of compound targets, the composition of the material flux along off-normal directions is largely determined by the ionization fraction of the target's constituent elements. ${ }^{110}$ This composition is different from that along directions close to the target normal, which is also influenced by the angular distribution of the neutral species. The effect of the deposition angle on the phase composition has been studied for the ternary system $\mathrm{Ti}-\mathrm{Si}-\mathrm{C},{ }^{110}$ which can allow for the formation of the so-called MAX phases [M is a transition metal, $\mathrm{A}$ is an A-group element (mostly IIIA and IVA), and X is C or N]. ${ }^{111}$ The formation of MAX phases is strongly dependent on the relative fractions of the constituent elements, i.e., the chemical composition. ${ }^{111}$ When a ternary $\mathrm{Ti}-\mathrm{Si}-\mathrm{C}$ target is sputtered, light elements like $\mathrm{C}$ are favored at the expense of heavier elements, such as $\mathrm{Ti}$ and $\mathrm{Si}$, along the target normal. ${ }^{112}$ On the other hand, substrates placed at an angle of $90^{\circ}$ with respect to the target experience a lower flux of $\mathrm{C}$ because of the lower ionization degree of $\mathrm{C}$ compared to $\mathrm{Ti}$ and $\mathrm{Si}$, i.e., predominantly ballistic transport of $\mathrm{C}$ in the forward direction. ${ }^{110}$ Worth pointing out is that with increasing process gas pressure $(>2 \mathrm{~Pa})$, more pronounced scattering of light elements to offnormal directions will occur. ${ }^{110}$ In Fig. 8, the x-ray diffraction patterns of Ti-Si-C films grown from a $\mathrm{Ti}_{2} \mathrm{SiC}_{3}$ target employing HiPIMS are presented. The TiC phase is the main

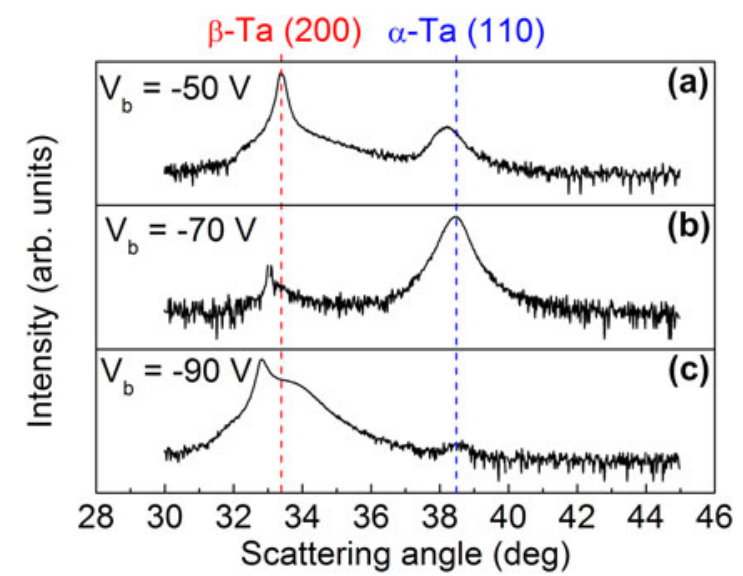

FIG. 7. X-ray diffraction patterns of Ta films deposited by HiPIMS on $\mathrm{Si}$ substrates biased at negative potentials of (a) -50 , (b) -70 and (c) $-90 \mathrm{~V}$. The bcc $\alpha$-Ta phase is obtained at $-70 \mathrm{~V}$ due to the ion bombardment-induced compressive stress. The vertical lines indicate the position of the $\beta$-Ta (200) and $\alpha$-Ta (110) peaks. Data taken from Alami et al. ${ }^{12}$

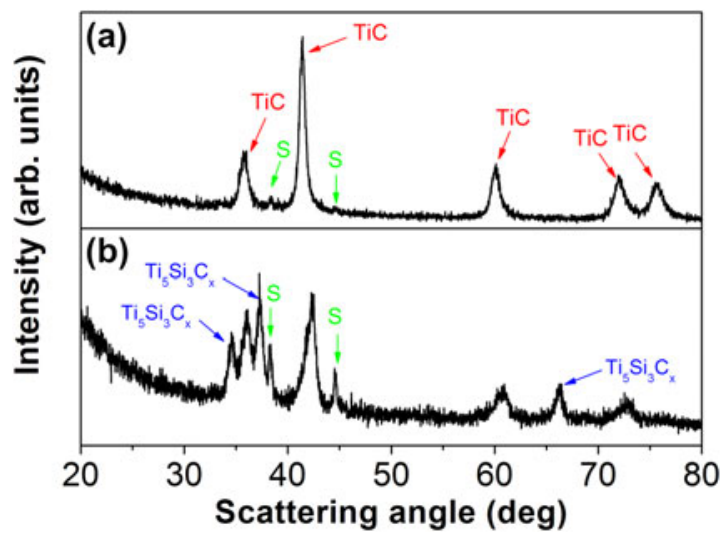

FIG. 8. X-ray diffraction patterns of Ti-Si-C films deposited on $\mathrm{MgO}$ (111) substrates by HiPIMS on substrates oriented (a) parallel and (b) perpendicular with respect to the target surface. Peaks of the $\mathrm{TiC}_{x}$ and $\mathrm{Ti}_{5} \mathrm{Si}_{3} \mathrm{C}_{x}$ phases are indicated by arrows, respectively. $\mathrm{S}$ stands for substrate peaks. Data taken from Alami et al. ${ }^{110}$

constituent for films grown on substrates parallel to the target surface [Fig. 8(a)]. At deposition angle of $90^{\circ}$, the socalled Nowotny's $\mathrm{Ti}_{5} \mathrm{Si}_{3} \mathrm{C}_{x}$ phase is also formed, as shown in Fig. 8(b).

Compound films can also be deposited from elemental targets when a reactive gas is added in the sputtering atmosphere. A typical example of a reactively synthesized material system in which HiPIMS can be used to control the phase composition is $\mathrm{TiO}_{2} .^{11,113-116}$ In general, $\mathrm{TiO}_{2}$ films can grow in an amorphous and in two tetragonal crystalline structures; the rutile and the anatase phases, respectively. ${ }^{117}$ The anatase phase exhibits interesting photocatalytic properties, ${ }^{117}$ whereas the rutile phase exhibits one of the highest refractive indices in nature. ${ }^{117}$ Deposition and/or annealing at high temperatures $\left(700-900{ }^{\circ} \mathrm{C}\right)$ have been reported to lead to the 
formation of the rutile phase. ${ }^{117}$ The anatase phase is generally obtained at lower temperatures, ${ }^{117}$ whereas deposition at room temperature often leads to the formation of amorphous films. ${ }^{117}$ In addition, the energetic bombardment by positively charged ions (facilitated by applying a negative bias voltage on the substrate) can promote the crystallization of $\mathrm{TiO}_{2}$ films at room temperature. ${ }^{118}$ When HiPIMS is used, the rutile phase can be achieved even at room temperature, and the increase of the flux of energetic species toward the growing film favors the formation of the rutile at the expense of the anatase phase. $^{11,113-115}$ This can be, for instance, achieved by increasing the peak target power (or current) ${ }^{115,116}$ (see Fig. 9) or by decreasing the working pressure during deposition. $^{113,114}$

\section{Control of film microstructure and interface engineering}

Polycrystalline films grown by PVD techniques exhibit a variety of microstructures with respect to the size, the morphology, and the relative orientation of the crystallites. ${ }^{91,119}$ These features have, for instance, implications for the mechanical strength ${ }^{120}$ and the electrical conductivity ${ }^{94,95,121}$ of the film. The microstructure is determined primarily by surface and bulk diffusion processes, ${ }^{91,119}$ which are controlled by the deposition temperature, the bombardment by energetic species, and the incorporation of impurities that act as inhibitors for the crystal and grain growth. ${ }^{91,119,122}$ Deposition at relatively low temperatures (typically lower than $0.4 \mathrm{~T}_{\mathrm{m}}$, where $\mathrm{T}_{\mathrm{m}}$ is the melting temperature of the deposited material) using state-of-the-art sputtering techniques allows only for surface diffusion to be activated leading to the formation of films with a columnar microstructure and intercolumnar porosity [see

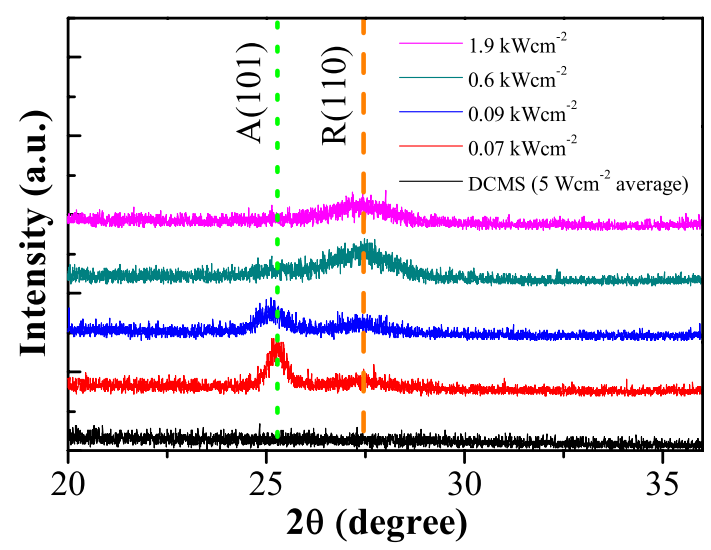

FIG. 9. X-ray diffraction patterns of $\mathrm{TiO}_{2}$ films grown on $\mathrm{Si}$ substrates by HiPIMS at various values of peak target power. The increase of the peak target power and the subsequent resulting increase in the number of ions available during deposition promote the formation of the rutile at the expense of the anatase phase. Adapted from Aiempanakit et al. ${ }^{115}$
Fig. 10(a) for CrN films]. ${ }^{31,91,119}$ Growth of films using HiPIMS is characterized by high ionic fluxes to the substrate (up to several hundreds of milliamperes per square centimeter) of relatively low energies (several tens of electronvolts), as was discussed in Section II B. These growth conditions trigger and/or enhance surface diffusion leading to film densification ${ }^{31,123}$ as shown in Fig. 10(b). Upon increasing the flux of ions available at the substrate (achieved, e.g., by increasing the peak target current), repeated nucleation occurs ${ }^{31,124}$ resulting in suppression of the columnar structure and transition from a dense polycrystalline to a globular nanocrystalline microstructure, ${ }^{31}$ as shown in Figs. $10(\mathrm{c})-10(\mathrm{~d})$. When high energetic fluxes are not available during growth, globular microstructures are consequence of segregation of impurity phases, which hinder the crystal and grain growth. It is, therefore, evident that the low-energy highflux ion irradiation during HiPIMS can be used to overcome the characteristically underdense and rough microstructures and obtain morphologies unique for low-temperature sputter deposition. ${ }^{31}$ This, in turn, allows growth of films with higher hardness, ${ }^{13,101,124}$ lower friction coefficient, ${ }^{13,125}$ and improved scratch and wear as well as corrosion resistance, ${ }^{13,124}$ as compared to films deposited by DCMS.

The highly ionized fluxes available in HiPIMS in combination with the use of a substrate bias result in ion energies in the order of several hundreds to thousands

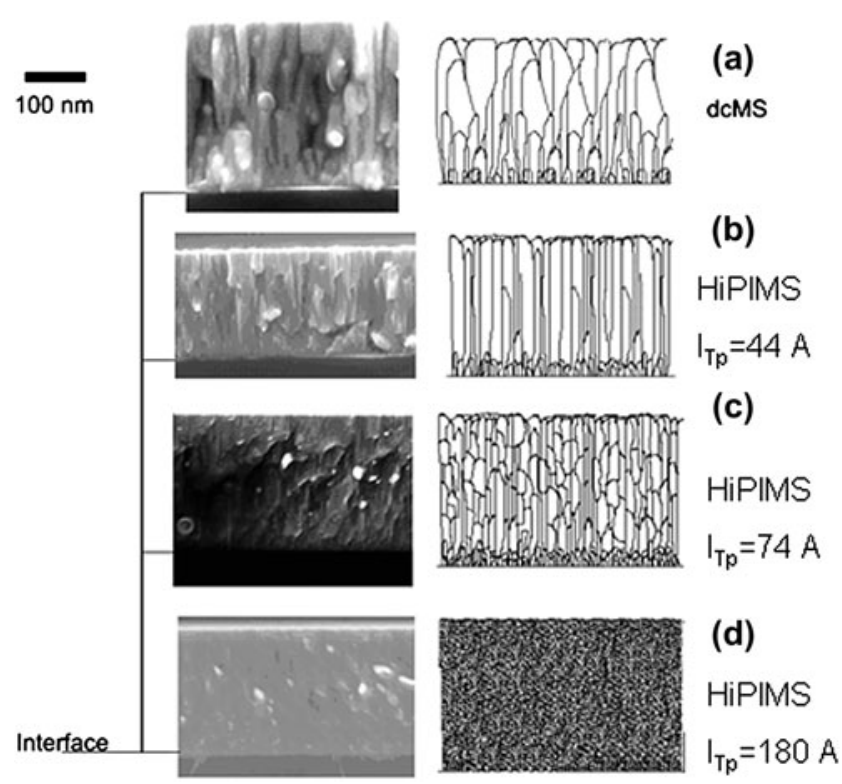

FIG. 10. Cross-sectional SEM images of $\mathrm{CrN}$ films deposited on Si by (a) DCMS, as well as HiPIMS at a peak target current of (b) $44 \mathrm{~A}$ $\left(1.0 \mathrm{~A} \mathrm{~cm}^{-2}\right)$, (c) $74 \mathrm{~A}\left(1.7 \mathrm{~A} \mathrm{~cm}^{-2}\right)$, and (d) $180 \mathrm{~A}\left(4.0 \mathrm{~A} \mathrm{~cm}^{-2}\right)$. The increase of the peak target current results in a transition of a dense polycrystalline morphology to a nanocrystalline featureless one. The sketches next to each SEM image serve merely as a schematic representation for the reader's convenience. Results taken from Alami et al. ${ }^{31}$ 
of electronvolts, which can be used to engineer the film-substrate interface and enhance the film adhesion. ${ }^{14}$ Typical example is a $\mathrm{CrN} / \mathrm{NbN}$ film deposited on steel substrates etched using HiPIMS (pretreatment by $\mathrm{Nb}^{+}$ions at a substrate bias voltage of $-1000 \mathrm{~V}$ ) exhibited a scratch test critical load $\left(\mathrm{L}_{\mathrm{c}}\right)$ of $56 \mathrm{~N}$, which was higher than the values of $25 \mathrm{~N}$ obtained for films deposited on substrates etched by a DCMS plasma (substrate bias voltage of $-1000 \mathrm{~V}$ at an Ar pressure of $0.8 \mathrm{~Pa}),{ }^{14}$ which exhibit a significantly lower ionization degree for both $\mathrm{Ar}^{+}$and metal ions. ${ }^{19}$ It should also be pointed out here that the $\mathrm{L}_{\mathrm{c}}$ values achieved on HiPIMS etched substrates are comparable to those for films grown on substrates cleaned using high fluxes of $\mathrm{Ar}^{+}$ions generated by an external ionization source. ${ }^{126}$ This fact indicates that HiPIMS can be used as an alternative process to improve the quality of the filmsubstrate interface and enhance the film adhesion, when no external source for increasing the Ar ionization is available.

\section{SUMMARY AND CONCLUDING REMARKS}

In this review on HiPIMS, the fundamental process characteristics as well as the most striking features when using this technique for surface treatment and thin film growth have been discussed. The HiPIMS discharge provides high plasma densities often resulting in a high degree of ionization of the sputtered material, which is shown to affect all types of plasma-wall interactions in a wide variety of plasma applications, such as etching, deposition of thin films, and surface modifications. HiPIMS today is an established IPVD technique within the sputtering community with dedicated sessions at international conferences on sputtering. Successful upscaling and industrialization of the process have been achieved, which has been followed by a continuously growing industrial interest reflected by the increasing number of publications using HiPIMS under industrial conditions. One very important aspect of future work on HiPIMS is the theoretical modeling, which has so far been reasonably successful in verifying experimental results regarding particle transport, gas rarefaction, electrical field and potential distributions, etc. To fully understand the underlying mechanisms operating in the HiPIMS discharge, more work in this area is needed, which ultimately must be connected to the plasma processing to achieve new and better thin films.

\section{ACKNOWLEDGMENTS}

The authors gratefully acknowledge Dr. Ante Hecimovic for valuable input. One of the authors (K. Sarakinos) acknowledges the Swedish Research Council (VR) for the financial support through the postdoctoral project 623-2009-7348.

\section{REFERENCES}

1. M. Ohring: Materials Science of Thin Films (Academic Press, San Diego, 2002).

2. F.M. Penning, U.S. Patent No: $2,146,025$ (1939) (German Patent filed 1935).

3. J.A. Thornton and A.S. Penfold: Cylindrical magnetron sputtering in thin film processes. Thin Film Processes, edited by J.L. Vossen and W. Kern (Academic Press, New York, 1978).

4. V. Kouznetsov, K. Macák, J.M. Schneider, U. Helmersson, and I. Petrov: A novel pulsed magnetron sputter technique utilizing very high target power densities. Surf. Coat. Tech. 122, 290 (1999).

5. U. Helmersson, M. Lattemann, J. Bohlmark, A.P. Ehiasarian, and J.T. Gudmundsson: Ionized physical vapor deposition (IPVD): A review of technology and applications. Thin Solid Films 513, 1 (2006).

6. A. Anders: Discharge physics of high power impulse magnetron sputtering. Surf. Coat. Tech. 205, S1 (2011).

7. J. Bohlmark, M. Lattemann, J.T. Gudmundsson, A.P. Ehiasarian, Y. Aranda Gonzalvo, N. Brenning, and U. Helmersson: The ionenergy distributions and plasma composition of a high power impulse magnetron sputtering discharge. Thin Solid Films 515, 1522 (2006).

8. M. Samuelsson, D. Lundin, J. Jensen, M.A. Raadu, J.T. Gudmundsson, and U. Helmersson: On the film density using high power impulse magnetron sputtering. Surf. Coat. Tech. 15, 591 (2010).

9. V. Sittinger, F. Ruske, W. Werner, C. Jacobs, B. Szyszka, and D. Christie: High power pulsed magnetron sputtering of transparent conducting oxides. Thin Solid Films 516, 5847 (2008).

10. M. Lattemann, U. Helmersson, and J.E. Greene: Fully dense, nonfaceted 111-textured high power impulse magnetron sputtering TiN films grown in the absence of substrate heating and bias. Thin Solid Films 518, 5978 (2010).

11. S. Konstantinidis, J.P. Dauchot, and M. Hecq: Titanium oxide thin films deposited by high-power impulse magnetron sputtering. Thin Solid Films 515, 1182 (2006).

12. J. Alami, P. Eklund, J.M. Andersson, M. Lattemann, E. Wallin, J. Bohlmark, P. Persson, and U. Helmersson: Phase tailoring of Ta thin films by highly ionized pulsed magnetron sputtering. Thin Solid Films 515, 3434 (2007).

13. J. Paulitsch, P.H. Mayrhofer, C. Mitterer, W-D. Münz, and M. Schenkel: Mechanical and tribological properties of $\mathrm{CrN}$ coatings deposited by a simultaneous HIPIMS/UBM sputtering process, in Society of Vacuum Coaters 50th Annual Technical Conference Proceedings, April 28-May 3 (Louisville, KY, 2007), p. 150.

14. A.P. Ehiasarian, J.G. Wen, and I. Petrov: Interface microstructure engineering by high power impulse magnetron sputtering for the enhancement of adhesion. J. Appl. Phys. 101, 054301 (2007).

15. J. Alami, P.O.A. Persson, D. Music, J.T. Gudmundsson, J. Bohlmark, and U. Helmersson: Ion-assisted physical vapor deposition for enhanced film properties on nonflat surfaces. J. Vac. Sci. Technol. A 23, 278 (2005).

16. A. Aijaz, D. Lundin, P. Larsson, and U. Helmersson: Dualmagnetron open field sputtering system for sideways deposition of thin films. Surf. Coat. Tech. 204, 2165 (2010).

17. E. Wallin, T.I. Selinder, M. Elfwing, and U. Helmersson: Synthesis of $\alpha-\mathrm{Al}_{2} \mathrm{O}_{3}$ thin films using reactive high-power impulse magnetron sputtering. Europhys. Lett. 82, 36002 (2008).

18. K. Sarakinos, J. Alami, and S. Konstantinidis: High power pulsed magnetron sputtering: A review on scientific and engineering state of the art. Surf. Coat. Tech. 204, 1661 (2010).

19. C. Christou and Z.H. Barber: Ionization of sputtered material in a planar magnetron discharge. J. Vac. Sci. Technol. A 18, 2897 (2000). 
20. S.M. Rossnagel and J. Hopwood: Metal ion deposition from ionized magnetron sputtering discharge. J. Vac. Sci. Technol. B 12, 449 (1994).

21. S. Konstantinidis, A. Ricard, M. Ganciu, J.P. Dauchot, C. Ranea, and M. Hecq: Measurement of ionic and neutral densities in amplified magnetron discharges by pulsed absorption spectroscopy. J. Appl. Phys. 95, 2900 (2004).

22. C. Nouvellon, S. Konstantinidis, J.P. Dauchot, M. Wautelet, P.Y. Jouan, A. Ricard, and M. Hecq: Emission spectrometry diagnostic of sputtered titanium in magnetron amplified discharges. J. Appl. Phys. 92, 32 (2002).

23. C.P. Johnson: The cathodic arc plasma deposition of thin films, in J.L. Vossen and W. Kern (eds.): Thin Film Processes II (Academic Press, New York, 1991).

24. W.D. Davis and H.C. Miller: Analysis of the electrode products emitted by dc arcs in a vacuum ambient. J. Appl. Phys. 40, 2212 (1969).

25. Z. Wang and S.A. Cohen: Hollow cathode magnetron. J. Vac. Sci. Technol. A 17, 77 (1999).

26. E. Klawuhn, G.C. D'Couto, K.A. Ashtiani, P. Rymer, M.A. Biberger, and K.B. Levy: Ionized physical-vapor deposition using a hollow-cathode magnetron source for advanced metallization. J. Vac. Sci. Technol. A 18, 1546 (2000).

27. D. Söderström: Modelling and Applications of the Hollow Cathode Plasma. Doctoral Thesis, Uppsala University, Uppsala, (2008).

28. S. Konstantinidis, J.P. Dauchot, M. Ganciu, A. Ricard, and M. Hecq: Influence of pulse duration on the plasma characteristics in high-power pulsed magnetron discharges. J. Appl. Phys. 99, 013307 (2006).

29. D. Lundin, N. Brenning, D. Jädernäs, P. Larsson, E. Wallin, M. Lattemann, M.A. Raadu, and U. Helmersson: Transition between the discharge regimes of high power impulse magnetron sputtering and conventional direct current magnetron sputtering. Plasma Sources Sci. Technol. 18, 045008 (2009).

30. E. Wallin and U. Helmersson: Hysteresis-free reactive high power impulse magnetron sputtering. Thin Solid Films 516, 6398 (2008).

31. J. Alami, K. Sarakinos, F. Uslu, and M. Wuttig: On the relationship between the peak target current and the morphology of chromium nitride thin films deposited by reactive high power pulsed magnetron sputtering. J. Phys. D 42, 015304 (2009).

32. J.T. Gudmundsson, P. Sigurjonsson, P. Larsson, D. Lundin, and U. Helmersson: On the electron energy in the high power impulse magnetron sputtering discharge. J. Appl. Phys. 105, 123302 (2009).

33. J. Bohlmark, J.T. Gudmundsson, J. Alami, M. Lattemann, and U. Helmersson: Spatial electron density distribution in a highpower pulsed magnetron discharge. IEEE Trans. Plasma Sci. 33, 346 (2005).

34. J.T. Gudmundsson: The high power impulse magnetron sputtering discharge as an ionized physical vapor deposition tool. Vacuum 84, 1360 (2010).

35. J. Vlcek, P. Kudlacek, K. Burcalova, and J. Musil: Ion flux characteristics in high-power pulsed magnetron sputtering discharges. Europhys. Lett. 77, 45002 (2007)

36. J. Bohlmark, J. Alami, C. Christou, A.P. Ehiasarian, and U. Helmersson: Ionization of sputtered metals in high power pulsed magnetron sputtering. J. Vac. Sci. Technol. A 23, 18 (2005).

37. K. Macák, V. Kouznetsov, J. Schneider, U. Helmersson, and I. Petrov: Ionized sputter deposition using an extremely high plasma density pulsed magnetron discharge. J. Vac. Sci. Technol. A 18, 1533 (2000).

38. B.M. DeKoven, P.R. Ward, R.E. Weiss, D.J. Christie, R.A. Scholl, W.D. Sproul, F. Tomasel, and A. Anders: Carbon thin film deposition using high power pulsed magnetron sputtering, in Society of Vacuum Coaters 46th Annual Technical Conference Proceedings, May 3-8 (San Francisco, CA, 2003), p. 158.

39. J.A. Hopwood: Plasma Physics. Thin Films: Ionized Physical Vapor Deposition, edited by J.A. Hopwood (Academic Press, San Diego, 2000).

40. S.M. Rossnagel and J. Hopwood: Magnetron sputter deposition with high levels of metal ionization. Appl. Phys. Lett. 63, 3285 (1993).

41. J. Vlcek, P. Kudlacek, K. Burcalova, and J. Musil: High-power pulsed sputtering using a magnetron with enhanced plasma confinement. J. Vac. Sci. Technol. A 25, 42 (2007).

42. K. Burcalova, A. Hecimovic, and A.P. Ehiasarian: Ion-energy distributions and efficiency of sputtering process in HIPIMS system. J. Phys. D 41, 115306 (2008).

43. A. Anders, J. Andersson, and A. Ehiasarian: High power impulse magnetron sputtering: Current-voltage-time characteristics indicate the onset of sustained self-sputtering. J. Appl. Phys. 102 113303 (2007)

44. J. Andersson, A.P. Ehiasarian, and A. Anders: Observation of $\mathrm{Ti}^{4+}$ ions in a high power impulse magnetron sputtering plasma. Appl. Phys. Lett. 93, 071504 (2008).

45. J. Rosén, A. Anders, S. Mráz, and J.M. Schneider: Charge-stateresolved ion energy distributions of aluminum vacuum arcs in the absence and presence of a magnetic field. J. Appl. Phys. 97, 103306 (2005).

46. A. Anders: Self-sputtering runaway in high power impulse magnetron sputtering: The role of secondary electrons and multiply charged metal ions. Appl. Phys. Lett. 92, 201501 (2008).

47. J. Andersson and A. Anders: Gasless sputtering: Opportunities for ultraclean metallization, coatings in space, and propulsion. Appl. Phys. Lett. 92, 221503 (2008).

48. L.I. Wei, M.A. Zhong-Quan, W. Ye, and W. De-Ming: Optimization of energy scope for titanium nitride films grown by ion beam-assisted deposition. Chin. Phys. Lett. 23, 178 (2006).

49. D. Lundin, P. Larsson, E. Wallin, M. Lattemann, N. Brenning, and U. Helmersson: Cross-field ion transport during high power impulse magnetron sputtering. Plasma Sources Sci. Technol. 17, 035021 (2008)

50. F. Eriksson, N. Ghafoor, F. Schäfers, E.M. Gullikson, and J. Birch: Interface engineering of short-period $\mathrm{Ni} / \mathrm{V}$ multilayer x-ray mirrors. Thin Solid Films 500, 84 (2006).

51. A. Hecimovic and A.P. Ehiasarian: Time evolution of ion energies in HIPIMS of chromium plasma discharge. J. Phys. D 42, 135209 (2009).

52. A. Hecimovic and A.P. Ehiasarian: Temporal evolution of the ion fluxes for various elements in HIPIMS plasma discharge. IEEE Trans. Plasma Sci. 39, 1154 (2011).

53. W.P. Leroy, S. Konstantinidis, S. Mahieu, R. Snyders, and D. Depla: Angular-resolved energy flux measurements of a dcand HIPIMS-powered rotating cylindrical magnetron in reactive and non-reactive atmosphere. J. Phys. D 44, 115201 (2011).

54. D. Lundin, M. Stahl, H. Kersten, and U. Helmersson: Energy flux measurements in high power impulse magnetron sputtering. J. Phys. D 42, 185202 (2009).

55. G. West, P. Kelly, P. Barker, A. Mishra, and J. Bradley: Measurements of deposition rate and substrate heating in a HiPIMS discharge. Plasma Processes Polym. 6, S543 (2009).

56. D.W. Hoffman: A sputtering wind. J. Vac. Sci. Technol. A 3, 561 (1985).

57. S.M. Rossnagel: Gas density reduction effects in magnetrons. J. Vac. Sci. Technol. A 6, 19 (1988).

58. A. Palmero, H. Rudolph, and F.H.P.M. Habraken: Gas heating in plasma-assisted sputter deposition. Appl. Phys. Lett. 87, 071501 (2005). 
59. A. Palmero, H. Rudolph, and F.H.P.M. Habraken: Study of the gas rarefaction phenomenon in a magnetron sputtering system. Thin Solid Films 515, 631 (2006).

60. I. Kolev and A. Bogaerts: Calculation of gas heating in a de sputter magnetron. J. Appl. Phys. 104, 093301 (2008).

61. S. Kadlec: Simulation of neutral particle flow during high power magnetron impulse. Plasma Processes Polym. 4, S419 (2007).

62. U. Helmersson, M. Lattemann, J. Alami, J. Bohlmark, A.P. Ehiasarian, and J.T. Gudmundsson: High power impulse magnetron sputtering discharges and thin film growth: A brief review, in Society of Vacuum Coaters 48th Annual Technical Conference Proceedings, April 23-28 (Denver, CO, 2005), p. 458.

63. D.J. Christie: Target material pathways model for high power pulsed magnetron sputtering. J. Vac. Sci. Technol. A 23, 330 (2005).

64. P. Poolcharuansin and J.W. Bradley: Short- and long-term plasma phenomena in a HiPIMS discharge. Plasma Sources Sci. Technol. 19, 025010 (2010).

65. S. Konstantinidis, J.P. Dauchot, M. Ganciu, and M. Hecq: Transport of ionized metal atoms in high-power pulsed magnetron discharges assisted by inductively coupled plasma. Appl. Phys. Lett. 88, 021501 (2006).

66. S.P. Bugaev, N.N. Koval, N.S. Sochugov, and A.N. Zakharov: Investigation of a high-current pulsed magnetron discharge initiated in the low-pressure diffuse arc plasma, in Proceedings of the XVIIth International Symposium on Discharges and Electrical Insulation in Vacuum, July 21-26 (Berkeley, CA, 1996), p. 1074.

67. J. Bohlmark, M. Östbye, M. Lattemann, H. Ljungcrantz, T. Rosell, and U. Helmersson: Guiding the deposition flux in an ionized magnetron discharge. Thin Solid Films 515, 1928 (2006).

68. A. Mishra, P.J. Kelly, and J.W. Bradley: The evolution of the plasma potential in a HiPIMS discharge and its relationship to deposition rate. Plasma Sources Sci. Technol. 19, 045014 (2010).

69. J. Emmerlich, S. Mráz, R. Snyders, K. Jiang, and J.M. Schneider: The physical reason for the apparently low deposition rate during high power pulsed magnetron sputtering. Vacuum 82, 867 (2008).

70. N. Brenning, R.L. Merlino, D. Lundin, M.A. Raadu, and U. Helmersson: Faster-than-Bohm Cross-B Electron Transport in Strongly Pulsed Plasmas. Phys. Rev. Lett. 103, 225003 (2009).

71. D. Lundin, U. Helmersson, S. Kirkpatrick, S. Rohde, and N. Brenning: Anomalous electron transport in high power impulse magnetron sputtering. Plasma Sources Sci. Technol. 17, 025007 (2008).

72. N. Brenning, C. Huo, D. Lundin, M.A. Raadu, C. Vitelaru, G.D. Stancu, T. Minea, and U. Helmersson: Understanding deposition rate loss in high power impulse magnetron sputtering. Plasma Sources Sci. Technol. (2011, in press).

73. M. Aiempanakit, T. Kubart, P. Larssron, K. Sarakinos, J. Jensen, and U. Helmersson: Hysteresis and process stability in reactive high power impulse magnetron sputtering of metal oxides. Thin Solid Films 519, 7779 (2011).

74. J. Lazar, J. Vlcek, and J. Rezek: Ion flux characteristics and efficiency of the deposition processes in high power impulse magnetron sputtering of zirconium. J. Appl. Phys. 108, 063307 (2010).

75. D. Horwat and A. Anders: Compression and strong rarefaction in high power impulse magnetron sputtering discharges. J. Appl. Phys. 108, 123306 (2010).

76. J. Lin, J.J. Moore, W.D. Sproul, B. Mishra, J.A. Rees, Z. Wu, R. Chistyakov, and B. Abraham: Ion energy and mass distributions of the plasma during modulated pulse power magnetron sputtering. Surf. Coat. Tech. 203, 3676 (2009).

77. L. Meng, A.N. Cloud, S. Jung, and D.N. Ruzic: Study of plasma dynamics in a modulated pulsed power magnetron discharge using a time-resolved Langmuir probe. J. Vac. Sci. Technol. A 29 011024 (2011)

78. M. Hála, J. Capek, O. Zabeida, J.E. Klemberg-Sapieha, and L. Martinu: Pulse management in high power pulsed magnetron sputtering process: I. Effect on the characteristics of Ar discharge and Nb coatings. J. Phys. D (2011, in press).

79. A.E. Ross, R. Sangines, B. Treverrow, M.M.M. Bilek, and D.R. McKenzie: Optimizing efficiency of Ti ionized deposition in HIPIMS. Plasma Sources Sci. Technol. 20, 035021 (2011).

80. S. Berg and T. Nyberg: Fundamental understanding and modeling of reactive sputtering processes. Thin Solid Films 476, 215 (2005).

81. D. Depla and R. De Gryse: Target poisoning during reactive magnetron sputtering: Part I: The influence of ion implantation. Surf. Coat. Tech. 183, 184 (2004).

82. D. Severin, O. Kappertz, T. Kubart, T. Nyberg, S. Berg, A. Pflug, M. Siemers, and M. Wuttig: Process stabilization and increase of the deposition rate in reactive sputtering of metal oxides and oxynitrides. Appl. Phys. Lett. 88, 161504 (2006).

83. W.D. Sproul, M.E. Graham, M.S. Wong, S. Lopez, D. Li, and R.A. Scholl: Reactive direct current magnetron sputtering of aluminum oxide coatings. J. Vac. Sci. Technol. A 13, 1188 (1995).

84. K. Sarakinos, J. Alami, C. Klever, and M. Wuttig: Process stabilization and enhancement of deposition rate during reactive high power pulsed magnetron sputtering of zirconium oxide. Surf. Coat. Tech. 202, 5033 (2008).

85. D. Depla and R. De Gryse: Cross section for removing chemisorbed oxygen from an aluminum target by sputtering. J. Vac. Sci. Technol. A 20, 521 (2002).

86. B. Clarenbach, B. Lorenz, M. Krämer, and N. Sadeghi: Timedependent gas density and temperature measurements in pulsed helicon discharges in argon. Plasma Sources Sci. Technol. 12, 345 (2003).

87. K. Sarakinos, J. Alami, and M. Wuttig: Process characteristics and film properties upon growth of TiOx films by high power pulsed magnetron sputtering. J Phys. D 40, 2108 (2008).

88. T. Kubart, M. Aiempanakit, J. Andersson, T. Nyberg, S. Berg, and U. Helmersson: Studies of hysteresis effect in reactive HiPIMS deposition of oxides. Surf. Coat. Tech. 205, S303 (2011).

89. D.M. Mattox: Handbook of Physical Vapor Deposition (PVD) Processing (Noyes Publications, Westwood, 1998).

90. O. Auciello and R. Kelly: Ion Bombardment Modification of Surfaces: Fundamentals and Applications (Elsevier, Amsterdam, 1984).

91. I. Petrov, P.B. Barna, L. Hultman, and J.E. Greene: Microstructural evolution during film growth. J. Vac. Sci. Technol. A $\mathbf{2 1}$, S117 (2003).

92. J. Dalla Torre, G.H. Gilmer, D.L. Windt, R. Kalyanaraman, F.H. Baumann, P.L. O’Sullivan, J. Sapjeta, T. Díaz de la Rubia, and M. Djafari Rouhani: Microstructure of thin tantalum films sputtered onto inclined substrates: Experiments and atomistic simulations. J. Appl. Phys. 94, 263 (2003).

93. W. Ensiger: Low energy ion assist during deposition-an effective tool for controlling thin film microstructure. Nucl. Instrum. Methods Phys. Res. B 127-128, 796 (1997).

94. C.R. Tellier and A.J. Tosser: Size Effects in Thin Films (Elsevier, Amsterdam, 1982).

95. R.C. Munoz, R. Finger, C. Arenas, G. Kremer, and L. Moraga: Surface-induced resistivity of thin metallic films bounded by a rough fractal surface. Phys. Rev. B 66, 205401 (2002).

96. H. Weis, T. Müggenburg, P. Grosse, L. Herlitze, I. Friedrich, and M. Wuttig: Advanced characterization tools for thin films in low-E systems. Thin Solid Films. 351, 184 (1999).

97. P. Siemroth and T. Schülke: Copper metallization in microelectronics using filtered vacuum arc deposition-principles and technological development. Surf. Coat. Tech. 133-134, 106 (2000). 
98. J. Alami, S. Bolz, and K. Sarakinos: High power pulsed magnetron sputtering: Fundamentals and applications. J. Alloy. Comp. 483, 530 (2009).

99. T. Schuelke, T. Witke, H.J. Scheibe, P. Siemroth, B. Schultrich, O. Zimmer, and J. Vetter: Comparison of DC and AC arc thin film deposition techniques. Surf. Coat. Tech. 120-121, 226 (1999).

100. R. Berisch: Sputtering by Particle Bombardment I (Springer, Berlin, 1982).

101. R. Chistyakov, B. Abraham, W.D. Sproul, J. Moore, and J. Lin: Modulated pulse power technology and deposition for protective and tribological coatings, in Society of Vacuum Coaters 50th Annual Technical Conference Proceedings, April 28-May 3 (Louisville, KY, 2007), p. 139.

102. T. Michely and J. Krug: Islands Mounts and Atoms (Springer, Berlin, 2004).

103. I. Petrov, F. Adibi, J.E. Greene, L. Hultman, and J.E. Sundgren: Average energy deposited per atom: A universal parameter for describing ion-assisted film growth? Appl. Phys. Lett. 63, 36 (1993).

104. G.C.A.M. Janssen and J.D. Kamminga: Stress in hard metal films. Appl. Phys. Lett. 85, 3086 (2004).

105. Y. Pauleau: Generation and evolution of residual stresses in physical vapour-deposited thin films. Vacuum 61, 175 (2001).

106. H. Windischmann: Intrinsic stress in sputter-deposited thin-films. Crit. Rev. Solid State Mater. Sci. 17, 547 (1992).

107. C.A. Davis: A simple model for the formation of compressive stress in thin films by ion bombardment. Thin Solid Films 226, 30 (1993).

108. L.A. Clevenger, A. Mutscheller, J.M.E. Harper, C. Cabral, and K. Barmak: The relationship between deposition conditions, the beta to alpha phase transformation, and stress relaxation in tantalum thin films. J. Appl. Phys. 72, 4918 (1992).

109. D.W. Face and D.E. Prober: Nucleation of body-centered-cubic tantalum films with a thin niobium underlayer. J. Vac. Sci. Technol. A 5, 3408 (1987)

110. J. Alami, P. Eklund, J. Emmerlich, O. Wilhelmsson, U. Jansson, H. Högberg, L. Hultman, and U. Helmersson: High-power impulse magnetron sputtering of $\mathrm{Ti}-\mathrm{Si}-\mathrm{C}$ thin films from a Ti3SiC2 compound target. Thin Solid Films 515, 1731 (2006).

111. M.W. Barsoum: TheMn+1AXn Phases: A new class of solids, thermodynamically stable nanolaminates. Prog. Solid State Chem. 28, 201 (2000).

112. P. Eklund, M. Beckers, U. Jansson, H. Högberg, and L. Hultman: The Mn+1AXn phases: Materials science and thin-film processing. Thin Solid Films 518, 1851 (2010).

113. J. Alami, K. Sarakinos, F. Uslu, C. Klever, J. Dukwen, and M. Wuttig: On the phase formation of titanium oxide films grown by reactive high power pulsed magnetron sputtering. J. Phys. D 42, 115204 (2009).

114. V. Stranak, M. Quaas, H. Wulff, Z. Hubicka, S. Wrehde, M. Tichy, and R. Hippler: Formation of TiOx films produced by high-power pulsed magnetron sputtering. J. Phys. D 41, 055202 (2008).

115. M. Aiempanakit, U. Helmersson, A. Aijaz, P. Larsson, R. Magnusson, J. Jensen, and T. Kubart: Effect of peak power in reactive high power impulse magnetron sputtering of titanium dioxide. Surf. Coat. Tech. 205, 4828 (2011).

116. R. Bandorf, M. Vergöhl, P. Giesel, T. Wallendorf, and G. Mark: Investigation of HPPMS titania thin films prepared by unipolar DC-superimposed and bipolar sputtering, in Society of Vacuum Coaters 50th Annual Technical Conference Proceedings, April 28-May 3 (Louisville, KY, 2007), p. 160.

117. M.D. Wiggins, M.C. Nelson, and C.R. Aita: Phase development in sputter deposited titanium dioxide. J. Vac. Sci. Technol. A 14, 772 (1996).

118. W. Zhou, X.X. Zhong, X.C. Wu, L.Q. Yuan, Q.W. Shu, W. Li, and Y.X. Xia: Low-temperature deposition of nanocrystalline TiO2 films: Enhancement of nanocrystal formation by energetic particle bombardment. J. Phys D 40, 219 (2007).

119. P.B. Barna and M. Adamik: Fundamental structure forming phenomena of polycrystalline films and the structure zone models. Thin Solid Films 317, 27 (1998).

120. J.S. Koehler: Attempt to design a strong solid. Phys. Rev. B 2, 547 (1970).

121. P.M. van Attekum, P.H. Woerlee, G.C. Verkade, and A.A. Hoeben: Influence of grain boundaries and surface Debye temperature on the electrical resistance of thin gold films. Phys. Rev. B 29, 645 (1984).

122. A. Anders: A structure zone diagram including plasma-based deposition and ion etching. Thin Solid Films 518, 4087 (2010).

123. G. Greczynski, J. Jensen, J. Böhlmark, and L. Hultman: Microstructure control of $\mathrm{CrN}_{x}$ films during high power impulse magnetron sputtering. Surf. Coat. Tech. 205, 118 (2010).

124. A.P. Ehiasarian, P.E. Hovsepian, L. Hultman, and U. Helmersson: Comparison of microstructure and mechanical properties of chromium nitride-based coatings deposited by high power impulse magnetron sputtering and by the combined steered cathodic arc/ unbalanced magnetron technique. Thin Solid Films 457, 270 (2004).

125. A.P. Ehiasarian, W-D. Münz, L. Hultman, U. Helmersson, and I. Petrov: High power pulsed magnetron sputtered $\mathrm{CrNx}$ films. Surf. Coat. Tech. 163-164, 267 (2003).

126. J. Vetter, T. Michler, and H. Steuernagel: Hard coatings on thermochemically pretreated soft steels: Application potential for ball valves. Surf. Coat. Tech. 111, 210 (1999). 